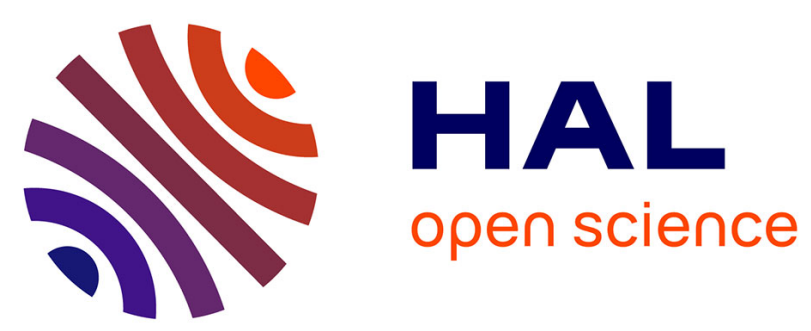

\title{
LOSS OF GAMETOPHYTIC \\ SELF-INCOMPATIBILITY WITH EVOLUTION OF INBREEDING DEPRESSION
}

Emmanuelle Porcher, Russell Lande

\section{- To cite this version:}

Emmanuelle Porcher, Russell Lande. LOSS OF GAMETOPHYTIC SELF-INCOMPATIBILITY WITH EVOLUTION OF INBREEDING DEPRESSION. Evolution - International Journal of Organic Evolution, 2005, 59, pp.46 - 60. 10.1111/j.0014-3820.2005.tb00893.x . mnhn-02265362

\section{HAL Id: mnhn-02265362}

\section{https://hal-mnhn.archives-ouvertes.fr/mnhn-02265362}

Submitted on 9 Aug 2019

HAL is a multi-disciplinary open access archive for the deposit and dissemination of scientific research documents, whether they are published or not. The documents may come from teaching and research institutions in France or abroad, or from public or private research centers.
L'archive ouverte pluridisciplinaire HAL, est destinée au dépôt et à la diffusion de documents scientifiques de niveau recherche, publiés ou non, émanant des établissements d'enseignement et de recherche français ou étrangers, des laboratoires publics ou privés. 
LRH: E. PORCHER AND R. LANDE

RRH: LOSS OF SELF-INCOMPATIBILITY

LOSS OF GAMETOPHYTIC SELF-INCOMPATIBILITY WITH EVOLUTION OF INBREEDING DEPRESSION

\author{
Emmanuelle Porcher ${ }^{1,2}$ and Russell Lande ${ }^{1,3}$ \\ ${ }^{1}$ Department of Biology, 0116, University of California - San Diego, La Jolla, CA, \\ 92093 \\ ${ }^{2}$ E-mail:eporcher@ucsd.edu \\ ${ }^{3}$ E-mail: rlande@ucsd.edu
}

Send page proofs to:

Russell Lande

Dept. of Integrative Biology

University of California

Berkeley, CA 94720-3140 
Abstract.-Gametophytic self-incompatibility (SI) in plants is a widespread mechanism preventing self-fertilization and the ensuing inbreeding depression, but it often evolves to self-compatibility. We analyze genetic mechanisms for the breakdown of gametophytic SI, incorporating a dynamic model for the evolution of inbreeding depression allowing for partial purging of nearly recessive lethal mutations by selfing, and accounting for pollen limitation and sheltered load linked to the $S$-locus. We consider two mechanisms for the breakdown of gametophytic SI: a non-functional $S$ allele and an unlinked modifier locus that inactivates the $S$-locus. We show that, under a wide range of conditions, self-compatible alleles can invade a self-incompatible population. Conditions for invasion are always less stringent for a non-functional $S$ allele than for a modifier locus. The spread of self-compatible genotypes is favored by extremely high or low selfing rates, a small number of $S$-alleles, and pollen limitation. Observed parameter values suggest that the maintenance of gametophytic SI is caused by a combination of high inbreeding depression in self-incompatible populations coupled with intermediate selfing rates of the self-compatible genotypes, and sheltered load linked to the $S$-locus.

Key words.-Competing selfing, delayed selfing, gametophytic self-incompatibility, lethal mutations, sheltered load, $S$-allele. 
Self-fertilization in hermaphroditic plants is favored by a $50 \%$ automatic selection advantage (Fisher 1941). In an outcrossing population, a rare selfing genotype will transmit three copies of its genome: two resulting from selfing all its own seeds, and one as a pollen parent of outcrossed seeds on other plants; by comparison, an outcrossing genotype transmits only two copies of its genome, one each as a seed and pollen parent from outcrossing with other plants. Inbreeding depression, defined as the relative decrease in the mean fitness of selfed vs. outcrossed individuals, is thought to be the only general factor strong enough to overcome the automatic advantage of selfing (Maynard Smith 1978; Lande and Schemske 1985; Charlesworth and Charlesworth 1987; Husband and Schemske 1996). In self-compatible species, outcrossing is therefore maintained in natural populations primarily by a high inbreeding depression (> 50\%) caused by mutation to recessive deleterious alleles. However, even with mechanisms such as herkogamy (spatial separation of pollen presentation and pollen receipt), dichogamy (temporal separation), or monoecy (separation of sexes in different types of flowers on the same plant), that prevent autogamous selfing (within flowers), appreciable selfing may be unavoidable in a self-compatible plant with multiple flowers blooming simultaneously, because pollinators often transfer pollen between flowers on the same plant (geitonogamous selfing, Barrett 2003).

Self-incompatibility, the ability of plants to recognize and reject self pollen, is thought to have evolved many times independently (Igic and Kohn 2001; Steinbachs and Holsinger 2002). Self-incompatibility (SI) mechanisms share a common ability to prevent the expression of inbreeding depression through both autogamous and geitonogamous self-fertilization, and may have evolved primarily in response to geitonogamy. A variety of genetic mechanisms underlying SI have been described (de 
Nettancourt 1997). Among them, $S$-RNase-based gametophytic SI seems to be the most common system and has been extensively studied (Roalson and McCubbin 2003). In this system, SI is controlled by a single multi-gene locus ( $S$-locus) requiring at least three alleles ( $S$-alleles), but many more (up to 100, Lawrence 1996) are often observed (Emerson 1939; Wright 1939; Lawrence 2000). The SI phenotype of pollen (gametophyte) is determined by its own haploid genotype, and the pistil $S$-locus product ( $S$-RNase) is a glycoprotein with ribonuclease activity.

$S$-RNase-mediated gametophytic SI is likely to have evolved only once (Igic and Kohn 2001; Steinbachs and Holsinger 2002) in the early evolution of angiosperms; it occurs in three highly diverged families (Solanaceae, Scrophulariaceae, and Rosaceae) and is potentially ancestral to most eudicots. However, plant families with selfincompatible species often contain a large proportion of self-compatible species. A recent study of mating system evolution in Solanaceae suggests that the loss of SI function is frequent and apparently irreversible (Igic et al. 2004).

Three conditions are associated with breakdown of SI and result in relatively large seed set by selfing: (1) a decrease in inbreeding depression, (2) a reduction in the number of alleles at the $S$-locus, and (3) outcross pollen limitation. These conditions could be triggered by a plant population bottleneck and/or failure of pollinators. Charlesworth and Charlesworth (1979) proposed a model for the breakdown of SI by invasion of a self-compatible allele at the $S$-locus, as a function of inbreeding depression only. Assuming constant inbreeding depression, they show that in species with singlelocus gametophytic SI, the conditions for invasion of a self-compatible mutant $S$-allele depend on the nature of the mutant, its primary selfing rate at fertilization, the number of $S$-alleles, and the inbreeding depression. A mutant $S$-allele with no activity in the style 
can always invade provided the inbreeding depression is small enough $(<0.6$, but this threshold depends on the primary selfing rate). In addition, a mutant suppressing $S$-allele pollen activity cannot invade if the number of $S$-alleles is large. Charlesworth and Charlesworth (1979) also predicted that another mechanism of loss of SI, by a mutation at an unlinked modifier locus that inactivates the $S$-locus (e.g. by extending budcompatibility), can invade when inbreeding depression is smaller than 0.5.

Charlesworth and Charlesworth's model does not account for the evolution of inbreeding depression during changes in the mating system of a population. Inbreeding depression is attributable both to nearly recessive, highly deleterious (lethal and semilethal) mutations and partially recessive (nearly additive), mildly deleterious mutations (Simmons and Crow 1977; Lande and Schemske 1985; Husband and Schemske 1996; Dudash and Carr 1998; Charlesworth and Charlesworth 1999). Selection acting on deleterious mutations with nearly additive effects depends little on the mating system of the population and this component of inbreeding depression can be considered roughly constant throughout evolution. In contrast, individually rare, nearly recessive, lethals and semi-lethals are much more likely exposed to selection as homozygotes in selfing populations than in randomly mating populations. Depending on the selfing rate and on the lethal mutation rate, this component of inbreeding depression can be partially purged by selfing (Lande and Schemske 1985; Lande et al. 1994). A rare self-compatible, partially selfing genotype invading a self-incompatible population will therefore experience a reduced inbreeding depression that may favor its evolution and the complete loss of SI.

We investigate the conditions for invasion of self-incompatible populations by self-compatible mutant alleles, incorporating a dynamic model for inbreeding 
depression, and hence the possible joint evolution of self-compatibility, self-fertilization, and inbreeding depression. Inbreeding depression is modeled by recurrent mutation to nearly recessive lethals at a very large number of loci (Kondrashov 1985), plus a constant component attributable to mildly deleterious mutations. We also analyze two additional factors likely to influence the breakdown of gametophytic SI. First, an advantage conferred by self-fertilization is the ability to produce seeds even when outcross pollen is scarce (Lloyd 1992; Holsinger 1996). This "reproductive assurance" is likely to play a role in the loss of SI, because self-incompatible populations are known to experience pollen limitation (e.g. Larson and Barrett 2000). Second, because the $S$-locus is situated in a region of the genome with restricted recombination (Coleman and Kao 1992), and because $S$-alleles are never homozygous when SI is functional, strong linkage disequilibrium may exist between some $S$-alleles and tightly linked recessive deleterious mutations that are never exposed to natural selection (Uyenoyama 1997; Stone 2004). This "sheltered load" will act to prevent the spread of self-compatible mutant $S$-alleles. We examine how the evolution of inbreeding depression, pollen limitation, and number of $S$-alleles affect the breakdown of gametophytic SI under two different genetic mechanisms: (1) invasion and spread of a non-functional mutant allele at the $S$-locus or (2) invasion and spread of a self-compatible mutation at an unlinked locus that inactivates the entire SI system in the style, for example by extending bud-compatibility to mature flowers.

TWO MODELS

General Description Inbreeding depression is analyzed using a modified version of Kondrashov's 
model (1985), to describe evolution of the distribution of number of heterozygous lethal alleles per individual in an infinite population. This model assumes a very large (effectively infinite) number of unlinked loci mutating to nearly recessive lethals; each mutation occurs at a new locus (or one not currently segregating in the population) and is therefore unique. Consequently, in an infinite population where outcrosses occur at random between unrelated individuals, homozygous lethals only appear by selfing. A multilocus genotype can be described by the number of heterozygous lethals, because lethals are never homozygous in mature plants and because all lethal mutations have identical effect on fitness, being lethal when homozygous and with the same dominance coefficient, $h$, when heterozygous. The inbreeding depression due to lethal mutations, $\delta$, is determined by the distribution of number of heterozygous lethals per individual (see Appendix). In addition, we also include a constant "background inbreeding depression", $d$, due to partially recessive (nearly additive), mildly deleterious mutations.

An unlinked $S$-locus is incorporated into this basic model of inbreeding depression and we monitor the changes in the frequency of an initially rare selfcompatible mutant in a self-incompatible population. We examine two genetic mechanisms likely to play a significant role in the breakdown of gametophytic SI in natural populations (Stone 2002): a non-functional (self-compatible) $S$-allele (e.g. created by deletion), affecting both the style and pollen specificities (Model 1) and a mutation at an unlinked modifier locus (e.g. a gene whose product is required by, or interferes with, the $S$-locus), affecting the rejection response of the style only (Model 2). These two models differ with respect to two major points. First, pollen carrying a mutant allele can (Model 2) or cannot (Model 1) be recognized by self-incompatible genotypes. 
Second, the effect of the mutation on the rejection response of the style affects any $S$ allele (Model 2) or the effect of the mutation is allelic (i.e., only affects one allele) and the mutation is linked to the allele it affects (Model 1).

In each of our models, a population undergoes mating, mutation and selection each generation. Transmission of lethals by selfing and outcrossing follows classical Mendelian laws (Appendix); the mating probabilities are controlled by the genotype at the $S$-locus (Model 1) or at the modifier locus and the $S$-locus (Model 2). Selfing rates and seed sets depend on pollen availability and on the $S$-locus genotypes (see below and Appendix). Mutation to lethals follows a Poisson process, with a mean number of new heterozygous lethals per genome of $U$ per generation. We assume multiplicative effects of heterozygous lethals on the fitness of individuals. We monitor the distributions of heterozygous lethal mutations for three (Model 1) or six (Model 2) classes of genotypes affecting the breakdown of gametophytic SI, as explained below.

\section{Genetic Mechanisms for the Breakdown of Gametophytic SI}

\section{Model 1 - Self-compatible allele at the S-locus}

We modified the model of Charlesworth and Charlesworth (1979) to describe the evolution of self-compatibility due to a non-functional mutant $S$-allele. The complete set of equations, including the genetic basis of inbreeding depression, is given in the Appendix. This model assumes isoplethy, or equal frequencies of $S$-alleles, which is maintained in infinite populations by frequency-dependent selection (Wright 1939; Finney 1952). Under this assumption, there is no need to examine the frequency of every $S$-locus genotype. Regardless of the number of $S$-alleles, the population can be described by the frequencies of three classes of genotypes at the $S$-locus: homozygous self- 
compatible genotypes $(\mathrm{CC})$, heterozygous, partially compatible genotypes $\left(\mathrm{I}_{\mathrm{i}} \mathrm{C}\right)$, and heterozygous self-incompatible genotypes $\left(\mathrm{I}_{\mathrm{i}} \mathrm{I}_{\mathrm{j}}\right)$. The mating probabilities differ among genotypes, as shown in the Appendix. Homozygous self-compatible genotypes CC may be affected by a sheltered load (Uyenoyama 1997), reducing their relative fitness by a factor $W_{\mathrm{CC}}$.

Model 2 - Modifier locus conferring self-compatibility

Although unlinked, the modifier locus and the $S$-locus are not independent, because $S$-locus homozygotes are only produced by selfing of self-compatible individuals. A positive association is therefore expected between the self-compatible allele at the modifier locus, $\mathrm{m}$, and homozygous genotypes at the $S$-locus. Because heterozygosity at the $S$-locus influences the probability of mating and the seed set (see below), such association is likely to affect the spread of the self-compatible allele. Assuming isoplethy, we consider six classes of genotypes to account for the association between the self-compatible (modifier) allele and the homozygous $S$-locus: homozygous self-compatible $m m I_{i} I_{j}$ and $m m I_{i} I_{i}$, heterozygous partially self-compatible $\mathrm{MmI}_{\mathrm{i}} \mathrm{I}_{\mathrm{j}}$ and $\mathrm{MmI}_{\mathrm{i}} \mathrm{I}_{\mathrm{i}}$, and self-incompatible $\mathrm{MMI}_{\mathrm{i}} \mathrm{I}_{\mathrm{j}}$ and $\mathrm{MMI}_{\mathrm{i}} \mathrm{I}_{\mathrm{i}}$ (see Table 1). Genotypes carrying two identical $S$-alleles may suffer a sheltered load, reducing their relative fitness by a factor $W_{\mathrm{CC}}$, which we assume is the same for all $S$-alleles. The hypothesis of isoplethy still applies for $S$-alleles in this model, because they are subject to equal frequencydependent selection (in a self-incompatible genotype), are neutral (in a self-compatible genotype) or are subject to identical selection from sheltered load. 
Individuals reproduce by outcrossing and, depending on their genotype, also by selfing. The selective properties of autogamous selfing are known to depend on the mode of self-fertilization (Lloyd 1992). Here, we consider two modes of selffertilization: (1) delayed selfing, which occurs at the end of anthesis, after opportunities for cross-pollination, and (2) competing selfing, where self and outcross pollen arrive simultaneously on the stigma and compete for the same ovules. Competing selfing is thought to be much more common than delayed (or prior) selfing, which often requires specific floral mechanisms (Holsinger 1991). However several theoretical (e.g. Lloyd 1992; Tsitrone et al. 2003) and experimental (Stewart et al. 1996; Stephenson et al. 2000) studies suggest a potentially important role of delayed selfing in the evolution of plant mating systems.

Under delayed selfing, the proportion of outcrossed seeds depends on outcross pollen availability only; hence, we assume that the selfing rate of self-compatible individuals is directly proportional to outcross pollen limitation. Different levels of outcross pollen availability are therefore modeled through different selfing rates of the homozygous self-compatible genotypes, $s$, and the relative seed set of self-incompatible vs. self-compatible genotypes is $1-s: 1$. We also assume that the amount of self pollen does not limit the seed set by partially or fully self-compatible genotypes. Thus the selfing rate of partially self-compatible individuals (heterozygous at the $S$-locus or at the modifier locus) is equal to the selfing rate $s$ of homozygous self-compatible individuals.

For competing selfing, we use a mass-action model (Holsinger 1991), where selfing rate is determined by the relative amounts of self pollen, $P_{s}$, vs. outcross pollen, $P_{o}$, landing on the stigma. We assume that all individuals receive the same ratio of outcross to self pollen. However, the proportion of effective pollen, not rejected by the 
stigma and available for fertilization, depends on the $S$-locus genotypes (Table 1). The selfing rate of self-compatible genotypes is the ratio of the amount of effective self pollen to the total amount of effective pollen landing on the stigma (Table 1). The seed set of different genotypes also depends on the amounts of self and outcross pollen: it is an increasing function of the total amount of effective pollen landing on the stigma (see Appendix). When outcross pollen is limited, self-compatible genotypes have larger seed sets than self-incompatible ones.

\section{Recursion Equations and Parameter Values}

The fitness of a genotype depends both on its viability and its male and female reproductive success. Viability of a genotype has three components: inbreeding depression due to nearly recessive lethals $(\delta)$, inbreeding depression due to nearly additive, mildly deleterious mutations $(d)$, and sheltered load associated with homozygous genotypes at the $S$-locus $\left(1-W_{\mathrm{CC}}\right)$. Male reproductive success, measured by the proportion of the population a genotype can fertilize, depends only on the SI properties of its pollen. Female reproductive success, measured by seed set, is determined by pollen availability and $S$-locus genotype.

The initial population is completely self-incompatible, containing only $\mathrm{I}_{\mathrm{i}} \mathrm{I}_{\mathrm{j}}$ (Model 1) or $\mathrm{MMI}_{\mathrm{i}} \mathrm{I}_{\mathrm{j}}$ (Model 2) genotypes, at mutation-selection equilibrium for lethals, with genomic mutation rate $U$ and dominance coefficient $h$. In the absence of selfing, the equilibrium distribution of number of heterozygous lethals in mature plants is Poisson with mean $U / h-U$ (see Appendix). A small frequency of the mutant allele (C or $\mathrm{m})$ is introduced in the population, in linkage equilibrium with lethal mutations and $S$-alleles. 
The recursion equations are iterated until closely approaching a new equilibrium.

Obtaining accurate estimates of the genomic mutation rate to lethals is difficult. Estimates range from $U=0.02$ (Drosophila melanogaster, Simmons and Crow 1977) to 0.2 (red mangroves, Klekowski and Godfrey 1989, extrapolated by Lande et al. 1994), depending notably on the duration of life cycle. We consider a larger range of values from $U=0$ to 1 . The dominance coefficient of lethals is $h=0.02$, as in the only available experimental data, which is from Drosophila (Simmons and Crow 1977). In an initially self-incompatible population at equilibrium, the range of $U=0$ to 1 with $h=0.02$ generates a mean number of heterozygous lethals per adult in the range of 0 to 49 , corresponding to an initial inbreeding depression due to lethals of $\delta=0$ to 0.999992 (see Appendix). The background inbreeding depression due to nearly additive, mildly deleterious mutations is $d=0$ or 0.25 (the latter value corresponding to estimates by Husband and Schemske 1996). The relative fitness of $S$-locus homozygotes (CC, Model 1 or $\mathrm{I}_{\mathrm{i}} \mathrm{I}_{\mathrm{i}}$, Model 2) is $W_{\mathrm{CC}}=1$ (no sheltered load) or 0.5 (as estimated by Stone 2004). We also vary the number of $S$-alleles in the population: $n=10,50$ (according to values observed in natural populations, Lawrence 2000) and $n=\infty$.

Pollen limitation is varied in two different ways depending on the mode of selffertilization. Under delayed selfing, we simply vary the selfing rate of self-compatible individuals from $s=0$ to 1 , which generates relative seed sets of self-incompatible vs. self-compatible individuals between 1:1 and 0:1. Under competing selfing, pollen limitation is modeled by different amounts of outcross pollen landing on the stigma (simulating e.g. a lack of pollinators or high geitonogamy), from $P_{o}=0.5$ to $\infty$. For a given amount of outcross pollen, the selfing rate of homozygous self-compatible 
individuals $s$ is controlled by varying the amount of self pollen landing on the stigma from $P_{s}=0$ to $\infty$, which generates selfing rates from $s=0$ to 1 . Although limitation of self pollen reduces the seed set by self-compatible genotypes, this always equals or exceeds that of self-incompatible genotypes. The range of the amount of outcross pollen $\left(P_{o}\right.$ from 0.5 to $\left.\infty\right)$ generates relative seed sets of self-incompatible vs. self-compatible individuals between $0.4: 1$ (strong pollen limitation, large selfing rate) and 1:1 (no pollen limitation or $s=0)$.

RESULTS

Competing Selfing

Results are expressed as the critical value of inbreeding depression due to lethals, $\delta$, in a completely self-incompatible population, above which a self-compatible mutant allele cannot invade (see figures). This critical inbreeding depression is plotted against the selfing rate of homozygous self-compatible genotypes, $s$. Each curve on a graph corresponds to a constant amount of outcross pollen landing on the stigma, $P_{o}$. Hence, variations in the selfing rate correspond to variations in the amount of self pollen landing on the stigma, $P_{s}$. In addition to the effects of pollen limitation and selfing rate, we consider the effects of the number of $S$-alleles, $n$, background inbreeding depression, $d$ and sheltered load, $1-W_{\mathrm{CC}}$, on the critical values of $\delta$.

\section{Model 1 - Self-compatible S-allele}

Figure 1

The conditions for invasion of a self-incompatible population by a selfcompatible $S$-allele depend on the selfing rate of the self-compatible genotype (Fig. 1). 
In a classical model assuming a constant inbreeding depression (Charlesworth and Charlesworth 1979), when the number of $S$-alleles is infinite $(n=\infty)$, in the absence of pollen limitation $\left(P_{o}=\infty\right)$, and with no background inbreeding depression $(d=0)$ or sheltered load $\left(1-W_{\mathrm{CC}}=0\right)$, the critical inbreeding depression due to lethals is $\delta=2 / 3$ when the selfing rate of self-compatible genotype, $s$, approaches zero. This threshold corresponds to a $2 / 3$ selective advantage of the $\mathrm{C}$ allele, attributable to the automatic advantage of selfing (0.5), and to nonrandom assortment of the $\mathrm{C}$ and I alleles in selfing heterozygous individuals, because of a rejection of I self pollen. However, a discontinuity exists at $s=0$, because self-compatible genotypes that do not self do not suffer inbreeding depression and the $\mathrm{C}$ allele is therefore neutral.

Our model allows inbreeding depression to evolve by purging homozygous lethals produced by selfing genotypes, which reduces the mean number of heterozygous lethals associated with self-compatible genotypes. Therefore, even for very small selfing rates, the critical inbreeding depression due to lethals in an initially self-incompatible population is slightly larger than $2 / 3$, at $\delta=0.682$ (Fig. 1A).

At higher selfing rate of the self-compatible genotype, the conditions for invasion become less restrictive; highly selfing genotypes $(s>0.8)$ can invade a self-incompatible population regardless of inbreeding depression. This strong effect of selfing on the critical $\delta$ is attributable to a partial purging of lethals, which is more efficient when the selfing rate is high (Lande and Schemske 1985). In a small region of the parameter space, with large $s$ and high $\delta$, there may occur two critical values of $\delta$ for a given $s$ (e.g. Fig. 1A). Below the lower critical value and above the upper critical value of $\delta$, the selfcompatible mutant invades, and in between it cannot invade. Because the region 
between the two critical values is small, it may rarely or never occur in reality and we do not consider it in the following.

A finite number of $S$-alleles provides an additional selective advantage to a selfcompatible allele with low selfing rate (Fig. 1B, C). For low numbers of $S$-alleles, the critical values of $\delta$ are dramatically increased at small selfing rates, and nearly outcrossing genotypes $(s<0.1)$ invade a self-incompatible population regardless of $\delta$. This selective advantage is due to differences between the male reproductive successes of the various $S$-locus genotypes: pollen carrying a self-compatible allele $\mathrm{C}$ fertilizes all genotypes, whereas pollen carrying a functional $S$-allele fertilizes a fraction $(n-2) / n$ of the population. This advantage affects the conditions for invasion, especially at low selfing rates, and increases when the number of $S$-alleles decreases.

Under pollen limitation, the conditions for invasion of a self-compatible allele are less stringent (Fig. 1A-C). The critical inbreeding depression can exceed 0.9 even under moderate pollen limitation. With sufficiently strong pollen limitation, a population with a small number of $S$-alleles $(n=10)$ is never resistant to invasion by a selfcompatible allele (Fig. 1C). This effect of pollen limitation, due to a larger seed set by self-compatible genotypes, can also be interpreted as a decrease in seed discounting (the loss of outcrossed seeds due to selfing, Lloyd 1992). Without pollen limitation, seed discounting is maximum: each selfing event occurs at the expense an outcrossing event. In contrast, with pollen limitation, increased selfing does not systematically result in a decrease in the number of outcrossed seeds, which is limited by pollen availability, and seed discounting decreases with increasing pollen limitation. The qualitative effect of the number of $S$-alleles remains the same whatever the pollen availability. 
Background inbreeding depression, $d$, and sheltered load, $1-W_{\mathrm{CC}}$, each have two effects on the conditions for invasion of a self-compatible allele (Fig. 1D-I). First, the critical inbreeding depression due to lethals is lowered at all selfing rates. Second, the threshold selfing rate, above which the conditions for invasion do not depend on $\delta$, is raised. Depending on pollen availability, an intermediate value of $\delta$ preventing invasion is sometimes restored for any selfing rate. With high sheltered load, the benefit of purging the component of inbreeding depression due to unlinked lethals is masked in most situations. With an infinite number of $S$-alleles $(n=\infty)$, the fate of a selfcompatible genotype with $s=0$ is also modified by a sheltered load (Fig. 1G). Because such genotypes suffer a load without benefiting from the automatic advantage of selfing or reproductive assurance, they can never invade a self-incompatible population.

In most cases, the invasion of a self-incompatible population by a self-

Figure 2 compatible allele is complete: the population evolves from full SI to full selfcompatibility. However, for some parameter values, stable polymorphisms occur, where the self-compatible allele coexists with a number of $S$-alleles. This is the case for a finite number of $S$-alleles under low selfing rates and high inbreeding depression (Fig. 2A), as well as for any number of $S$-alleles with any selfing rate when the self-compatible allele suffers a sheltered load (Fig. 2B). In such situations, the deleterious effects of inbreeding depression and genetic load are exactly counterbalanced by the benefits of selfcompatibility.

\section{Model 2 - Modifier locus}

The conditions for invasion of a self-incompatible population by a self- 
compatible allele at a modifier locus also depend on the selfing rate, $s$, of the selfcompatible genotype (Fig. 3). In classical models assuming a constant inbreeding depression (Charlesworth and Charlesworth 1979), with no pollen limitation and no sheltered load, regardless of the number of $S$-alleles, the critical inbreeding depression due to lethals is $\delta=1 / 2$, as for a locus modifying the selfing rate in a self-compatible population (Maynard Smith 1978). This occurs because with no pollen limitation selfincompatible genotypes have the same mean fitness as would occur in a completely outcrossing self-compatible population.

Our model allows purging of lethals by selfing in self-compatible genotypes. Therefore, even at very small selfing rates near zero, the critical inbreeding depression is slightly larger than 0.5 , at $\delta=0.514$ (Fig. 3A). However, if self-compatible genotypes are completely outcrossing $(s=0)$, the self-compatible allele is neutral, as explained above. As for Model 1, the critical inbreeding depression increases with $s$, due to partial purging of nearly recessive lethals in self-compatible genotypes. Thus, highly selfing genotypes $(s>0.8)$ can invade regardless of the value of inbreeding depression.

When outcross pollen is not limited, the conditions for invasion do not depend on the number of $S$-alleles (Fig. 3A-C), because the self-compatible allele at the modifier locus does not affect the SI properties of pollen, and the male reproductive success of an individual does not depend on its $S$-locus genotype. As for Model 1, the conditions for invasion are less restrictive under pollen limitation, allowing the spread of a selfcompatible allele under high levels of inbreeding depression. Pollen limitation interacts with the number of $S$-alleles: because self-compatible genotypes accept all outcross pollen, they suffer less from pollen limitation than self-incompatible genotypes, which 
reject a fraction $2 / n$ of outcross pollen grains. The self-compatible allele benefits from this increased seed set at small selfing rates only, when the effects of inbreeding depression are limited. For small selfing rates, with a finite number of $S$-alleles, a selfcompatible allele can invade a self-incompatible population whatever the level of inbreeding depression due to lethals.

As in Model 1, with background inbreeding depression the conditions for invasion are more stringent, especially at high selfing rates (Fig. 3D-F). With no pollen limitation and $d=0.25$, the critical inbreeding depression due to lethals is slightly larger than $1 / 3$, at $\delta=0.352$, when $s$ approaches 0 , which corresponds to a total inbreeding depression equal to the critical value of $0.514=1-(1-\delta)(1-d)$.

The effect of a sheltered load exhibits some difference compared to Model 1. When the number of $S$-alleles is infinite, a sheltered load prevents the spread of a selfcompatible allele, even for moderate values of $\delta$ (from 0.1 to 0.8 , Fig. $3 \mathrm{G}$ ). With a finite number of $S$-alleles, the invasion of a self-compatible allele producing low selfing rates depends strongly on pollen availability (Fig. $3 \mathrm{H}, \mathrm{I}$ ). A fraction $1 / n$ of the outcrossed offspring of a self-compatible genotype becomes homozygous at the $S$-locus and suffers the sheltered load. Hence, when self-compatible genotypes reproduce mainly by outcrossing, they are counter-selected and cannot invade. As $s$ increases, the selfcompatible allele can invade, even without pollen limitation, because of partial purging of lethals and the automatic advantage of selfing. When outcross pollen is limited, the higher seed set of self-compatible genotypes completely counterbalances the loss of fitness from selfing at low selfing rates. The effect of a sheltered load on the spread of a self-compatible allele depends on the assumption that the linked load is identical for all 
$S$-alleles: variance in the sheltered load among $S$-alleles would destroy isoplethy and reduce the effective number of $S$-alleles and the sheltered load on the population. Stable polymorphisms are observed with a sheltered load $\left(1-W_{\mathrm{CC}}=0.5\right)$, under high selfing rates, whatever the number of $S$-alleles (Fig. 4). The trend is opposite to that observed for Model 1 (Fig. 2B): the highest frequency of the self-compatible allele occurs at a low selfing rate in Model 2, whereas it occurs at a high selfing rate in Model 1. This difference arises because the sheltered load does not depend on the selfing rate in Model 1: all homozygous self-compatible genotypes are affected, and they invade more easily when the inbreeding depression due to lethals is purged, at a high selfing rate. In contrast, the effect of the sheltered load is increased at a high selfing rate in Model 2, because the association of self-compatible genotypes with homozygous genotypes at the $S$-locus depends strongly on the selfing rate.

\section{Delayed Selfing}

Under delayed selfing, in both models of the breakdown of gametophytic SI, a self-compatible allele is either neutral (infinite number of $S$-alleles, $n=\infty$, and no pollen limitation, $P_{o}=\infty$ ) or always invades a self-incompatible population regardless of inbreeding depression (finite number of $S$-alleles, Model 1, and/or pollen limitation, Model 1 and 2). This occurs because delayed selfing does not affect the number of outcrossed seeds produced by self-compatible individuals, which is always identical to that produced by self-incompatible individuals (no seed discounting). Under pollen limitation, selfing individuals have an advantage because of a larger seed set than selfincompatible individuals, even if inbreeding depression is high. In addition, when the number of $S$-alleles is finite, in Model 1 the self-compatible allele benefits from its 
ability to pollinate any $S$-locus genotype. Stable polymorphism occurs only in a very small region of parameter space, with sheltered load and very high inbreeding depression due to lethals $(\delta>0.98)$.

\section{DISCUSSION}

Our models were primarily developed to account for the breakdown of $S$-RNasebased gametophytic SI, the most phylogenetically widespread mechanism of SI. These models can nevertheless be applied to other mechanisms of gametophytic SI controlled by a single locus encoding style- and pollen-specific molecules. These conditions are met in Papavaraceae, where gametophytic SI involves a signal transduction cascade triggered by the interaction between stigmatic $S$-proteins and pollen $S$-receptors (Franklin-Tong and Franklin 2003). In contrast, gametophytic SI in Poaceae is controlled by two unlinked genes ( $\mathrm{S}$ and Z, Li et al. 1997) and the conditions for breakdown of SI are likely to differ from those predicted by our models. Sporophytic SI, in which the diploid genotype of the pollen parent determines specificity, has been found in seven families, and probably involves different mechanisms, although only one has been fully characterized (in Brassicaceae, Hiscock and Tabah 2003). Regardless of the molecular details, complex dominance relationships occur among $S$-alleles in sporophytic SI. Consequently, one major assumption of our model, identical frequencies of $S$-alleles, is not met and the predictions above do not apply to breakdown of sporophytic SI. Our discussion therefore focuses on gametophytic SI; we examine its actual breakdown in natural populations, and discuss the conditions maintaining gametophytic SI. 


\section{Frequent Breakdown of Gametophytic SI}

Our models for the breakdown of gametophytic SI account for the joint evolution of inbreeding depression, and for pollen limitation and a sheltered load. The models show that SI can breakdown and become lost completely in large populations under a wide range of conditions, depending on the selfing rate of the self-compatible genotypes. First, under pure delayed selfing, there is no obstacle to the spread of a self-compatible allele. Second, under competing selfing, unless the number of $S$-alleles is very large (Model 1) and outcross pollen is never limited (Model 2), a self-compatible allele producing a small selfing rate can always invade a self-incompatible population. Third, for larger selfing rates, a self-incompatible population with a high inbreeding depression due to lethals is impervious to invasion by a self-compatible allele only if the number of $S$-alleles is large, outcross pollen is not limited, or if $S$-alleles suffer a strong sheltered load.

Available experimental data suggest that the conditions on number of $S$-alleles and pollen limitation favoring maintenance of gametophytic SI are actually not met in most natural populations. First, although frequency-dependent selection in selfincompatible populations maintains higher numbers of $S$-alleles than under neutrality, these numbers remain limited and are expected to generate an advantage $n /(n-2)$ for self-compatible vs. self-incompatible alleles, via larger male reproductive success. Typical estimated numbers of $S$-alleles per population range between $n=10$ and 50 (Lawrence 2000); larger numbers (e.g. > 100 for two Trifolium species, Lawrence 1996) are generally considered an exception and the reasons for their maintenance remain unknown (Lawrence 2000). These values can be directly compared to those used in our model, because numbers of alleles are generally estimated assuming isoplethy (e.g. 
Paxman 1963) and thus correspond to effective numbers of isoplethic alleles.

Second, pollen limitation is common in Angiosperms: 62\% of 258 studied species showed significantly larger seed set when flowers were provided with supplemental pollen, at least at some times or in some locations (Burd 1994). A comparative analysis demonstrated that self-incompatible species exhibit more pollen limitation than species that can self-fertilize: the relative seed set of open-pollinated flowers vs. flowers receiving supplemental pollen was 0.41:1 in self-incompatible species and 0.69:1 in self-compatible species (Larson and Barrett 2000). Such values indicate that the expected ratio of seed set by self-incompatible genotypes to seed-set by selfing, self-compatible genotypes, as used in our approach, is between 0.4 and 0.6 , which corresponds to the two smallest amounts of outcrossed pollen considered in this $\operatorname{model}\left(P_{o}=0.5\right.$ and 1$)$.

Given these values of number of $S$-alleles and seed set due to pollen limitation in natural populations, the regions of parameter space where gametophytic SI is expected to breakdown are quite large for both models (Figs. 1 and 3), although the conditions for invasion are somewhat less restrictive for a self-compatible allele at the $S$-locus (Model 1) than at a modifier locus (Model 2). In some cases, self-compatible mutants can invade regardless of the inbreeding depression and of their selfing rate (see e.g. Fig. 1F).

\section{Breakdown of SI in Natural Populations}

\section{Molecular mechanisms}

Our models indicate that the dynamics of invasion of a self-compatible mutant in a self-incompatible population depend primarily on two characteristics of molecular mechanisms conferring self-compatibility: affected functions (e.g. a mutation disrupting 
pollen function in addition to style function benefits from an increased male reproductive success) and allelic specificity of the self-compatible mutation combined with linkage to the $S$-locus (a mutation with allele-specific effects, if linked to the $S$ locus, benefits from nonrandom assortment of gametes in selfing heterozygous individuals). Our results show that the least restrictive conditions for invasion occur for mutations within the $S$-locus with allelic effects influencing both style and pollen function (e.g. a self-compatible $S$-allele).

Although $S$-RNase-based gametophytic SI has been widely studied and the $S$ locus has been located in many species, little is known about the molecular details of pollen recognition and rejection, and data on the molecular mechanisms responsible for self-compatibility does not always carry information regarding the characteristics listed above. The role of $S$-RNase is well understood, but the pollen self-incompatibility determinant has been identified only quite recently (Sijacic et al. 2004), and other proteins may also be involved in the self-incompatibility interactions (Kondo et al. 2002). Study of spontaneous or induced self-compatible mutants has led to the recognition of three categories of molecular mechanisms responsible for the breakdown of gametophytic SI, based on knowledge of $S$-RNases: (1) a duplication of the $S$-locus, affecting the specificity of pollen via yet unknown mechanisms, (2) mutations that affect the production of $S$-RNase with allele-specific effects, and (3) mutations that do not affect the production of $S$-RNase, with allelic as well as non-allelic effects (Stone 2002).

Comparison of self-compatible and self-incompatible populations within a species, or such species within a genus, provides some useful information on how gametophytic SI breaks down in nature (reviewed for Solanaceae in Stone 2002). Although the available data are too scarce to derive quantitative information about the 
relative frequency of different mechanisms, some patterns can be discerned. First, a duplication of the $S$-locus has been ruled out as a major cause of the breakdown of SI in natural populations of the genus Nicotiana. Second, mutations affecting $S$-RNase activity, with allelic-specific effects, seem to be commonly associated with loss of SI in natural populations (Stone 2002). Although we did not consider the fate of a mutation at the $S$-locus affecting the style response only, it can be inferred from the results of Models 1 and 2. Such a mutation located at the $S$-locus and with allelic effect would benefit from a 2/3 selective advantage, as for Model 1 . But in contrast to Model 1, a selfcompatible genotype would not benefit from a higher male reproductive success, because the pollen $S$-gene is still functional. Hence, the conditions for invasion of such mutations are expected to resemble those of Model 1 with an infinite number of $S$ alleles, except in case of pollen limitation, where self-compatible genotypes with a small selfing rate would be advantaged, similar to Model 2 .

However, the observation of a correlation between loss of $S$-RNase activity and self-compatibility does not inform directly on the main evolutionary forces involved in the breakdown of SI. Although some cases of self-compatible point mutations within the ribonuclease are well documented (e.g. Royo et al. 1994), it is usually not known whether the loss of $S$-RNase activity is caused by a point mutation within the $S$-locus or by action of a modifier gene. Furthermore, most attention has been paid to the style component of SI, because little was known about the pollen $S$-gene for gametophytic SI until recently (Ushijima et al. 2003; Sijacic et al. 2004). Hence, self-compatibility has been mostly attributed to deficiencies in the style response (but see Golz et al. 2000 and references therein; Tsukamoto et al. 2003), with little regard for possible joint loss of function in pollen. 
In summary, it appears that no single mechanism is predominantly responsible for breakdown of SI in natural populations. All types of mutations conferring SI, affecting the style and/or the pollen component of SI, with allele-specific or non-allelic effect, and located within or outside the $S$-locus, have been observed at least once in natural populations. Our model predicts that the conditions for invasion of a selfincompatible population are less restrictive for mutations within the $S$-locus with allelic effects influencing both style and pollen function. Especially in light of the recent identification of the pollen part gene, more data are needed to clarify the respective roles of different classes of mutations in the breakdown of SI.

\section{Polymorphic populations}

Several populations polymorphic for SI have been reported, but they appear to be rare and perhaps transitory (Stone 2002). Two exceptions deserve our attention. Ando et al. (1998) found that 42 of 79 studied populations of Petunia axillaris contained both self-compatible and self-incompatible individuals, which strongly suggest that such polymorphism might be stable. J. Stone (pers. comm. 2004), studying terminal branch length of $S$-RNase alleles in Witheringia solanacea, showed that two self-compatible alleles, co-segregating with functional $S$-alleles in natural populations, have persisted long enough in the populations to diverge from each other. Such evidence of stable polymorphism could indicate the presence of sheltered load, preventing a complete invasion by self-compatible alleles.

\section{Influence of demography}

Natural populations have finite size, and variations in the number of individuals 
might influence the evolution of gametophytic SI. Although our models assume an infinite population size, some effects of a decrease in population size can be inferred. A bottleneck is expected to decrease the effective number of $S$-alleles in a population, due either to loss of alleles or to anisoplethy (Wright 1939). It can also result in purging of some of the inbreeding depression, especially that due to lethals (Lande and Schemske 1985; Bataillon and Kirkpatrick 2000; Hedrick 2002), although the purging of lethals by selection and inbreeding in a finite population is of course a stochastic process (Lacy et al. 1996; Lacy and Ballou 1998; Byers and Waller 1999). A population bottleneck may decrease outcross pollen availability via reduced population density and increased isolation (e.g. Kunin 1997). Hence, our results indicate that a bottleneck could strongly favor the breakdown of gametophytic SI. Breakdown of SI subsequent to a bottleneck has in fact been observed for several species with sporophytic or heteromorphic SI (Barrett et al. 1989; Reinartz and Lez 1994). In addition, many examples of selfcompatible populations located on the edges a self-incompatible species' range have been documented (Stebbins 1957, 1974), suggesting that SI tends to breakdown in small, isolated populations.

\section{Factors Maintaining Gametophytic SI in Natural Populations}

Although $S$-RNase based gametophytic SI is thought to have disappeared frequently throughout the evolution of angiosperms (Igic et al. 2004), it still exists in at least 3 of the 60 families of Angiosperms exhibiting gametophytic SI (Kao and McCubbin 1996). The prediction of our models, that gametophytic SI should breakdown frequently, depends on the values of several parameters in natural populations, discussed below. 


\section{Selfing rate of a self-compatible mutant}

If self-compatible mutants exhibit delayed self-fertilization, gametophytic SI always breaks down and becomes lost completely. However, competing selfing is far more common, because it is unavoidably involved in geitonogamous self-fertilization and because pure delayed selfing requires specific floral mechanisms that prevent the release of self pollen on the stigma in young flowers but favor it in old flowers (Holsinger 1991). Delayed self-fertilization might also be promoted by a greater competitive ability of outcross vs. self pollen (pollen prepotency or cryptic selfincompatibility, Lloyd and Schoen 1992) but this is unlikely to coexist with functional gametophytic self-incompatibility. Hence, we expect delayed selfing to co-occur with competing selfing in newly arisen self-compatible genotypes.

Under competing selfing, self-compatible mutants with extremely high or low selfing rates are expected to invade in a self-compatible population regardless of the inbreeding depression. However, we expect the selfing rate of a new self-compatible mutant to be intermediate rather than near 0 or 1 . First, the selfing rate is expected to be substantially larger than zero, because of the inevitable component of selfing due to geitonogamy (Barrett 2003). Second, very high selfing rates are also unlikely to appear. Mechanisms such as herkogamy or dichogamy are found equally in self-compatible and self-incompatible species (e.g. Bertin 1993 for dichogamy) and are therefore thought to have evolved to avoid interference between male and female function (e.g. preventing clogging of stigmas by self pollen, Lloyd and Webb 1986; Webb and Lloyd 1986; Barrett 2003) as much as to reduce self-fertilization. Finally, several studies of the genetics of plant mating systems suggest that the evolution of a high selfing rate is in 
general not monogenic (McNair and Cumbes 1989; Fenster and Ritland 1994; Fishman et al. 2002), although it may sometimes be under control of major genes only (Fenster and Barrett 1994; Georgiady et al. 2002). A single mutation producing a very high selfing rate in a self-compatible genotype may be likely to have very deleterious pleiotropic effects (Fisher 1958; Wright 1968).

\section{Inbreeding depression}

With competing selfing and an intermediate selfing rate of the self-compatible mutants, our model indicates that SI can be stable if inbreeding depression is high. Little is known about inbreeding depression in populations of self-incompatible species, because it is difficult, by definition, to obtaining inbred genotypes in such species. However, inbreeding depression is expected to be high in self-incompatible populations since nearly recessive lethal mutations are not purged in the absence of selfing, except by weak selection against their heterozygous effects. To our knowledge, only two experimental evaluations of inbreeding depression in a self-incompatible population have been conducted, using either bud-pollination (Levin and Bulinska-Radomska 1988) or partial SI (Vogler et al. 1999) to circumvent SI, and respectively yielding estimated inbreeding depression of 0.324 and 0.98 . These values are likely underestimates, because the early component of inbreeding depression (e.g. embryo death) was ignored. In self-compatible species, early inbreeding depression usually is measured by comparing seed sets from selfing and outcrossing. For self-incompatible species, differences between these seed sets may be caused either by inbreeding depression or residual SI. High early inbreeding depression in many predominantly outcrossing selfcompatible species (Lande et al. 1994; Husband and Schemske 1996) also suggests that 
total inbreeding depression may be high in self-incompatible species. Clearly there is a need for more estimates of inbreeding depression in SI species.

\section{Pollen discounting}

Pollen discounting, wherein the use of pollen for selfing results in a decrease in the amount of pollen exported to other plants, not incorporated in this model, also might prevent the spread of self-compatible alleles by reducing the male reproductive success of self-compatible genotypes (Holsinger 1991; Harder and Wilson 1998). However, there is no obvious reason why more self pollen should be lost for exportation in a selfcompatible mutant than in the original self-incompatible genotypes, so pollen discounting should not be a major factor accounting for the maintenance of selfincompatibility.

\section{Sheltered load}

A genetic load tightly linked to the $S$-alleles was suspected in the early literature (Mather and de Winton 1941). Some authors have observed the death of homozygotes at the $S$-locus (Richards 1998), but it has not been clearly attributed to a sheltered load. The most convincing evidence is provided by Stone (2004), who distinguished the relative effects of sheltered load, inbreeding depression and residual SI on the seed set obtained by bud pollination. The estimated sheltered load differs considerably between $S$-alleles and ranges between 0 (for the majority of alleles) and 0.62 . No general conclusion can be driven from these data concerning a single population, but the observation of several alleles without any detectable load suggests that sheltered load might not be systematically involved in the maintenance of SI: a mutation conferring self- 
compatibility can easily invade if it is linked to an $S$-allele with no sheltered load.

\section{Concluding Remarks}

$S$-RNase-based gametophytic SI has been lost numerous times during the evolution of Angiosperms (Igic and Kohn 2001; Igic et al. 2004). Our theoretical results confirm that gametophytic SI can break down under a wide range of conditions. The maintenance of SI in one third to one half of extant Angiosperm species can also be explained by our models. In view of experimental data on number of $S$-alleles $(n \approx 50)$ and pollen limitation, our results suggest that the most probable explanation for the maintenance of SI is either a strong sheltered load for most $S$-alleles or a very high inbreeding depression due to lethals $(\delta>0.8$ or 0.9 ) maintained by high genomic mutation rate to lethals $(U \approx 0.2)$, combined with intermediate selfing rates of selfcompatible mutants. These quantities are of central importance for the maintenance or breakdown of SI and are not well documented at present. In addition, Igic et al. (2004) propose that SI may be maintained in the long term by the macro-evolutionary advantage of a higher rate of taxonomic diversification (e.g. due to higher extinction rate of predominantly selfing species) despite the frequent irreversible transition to selfcompatibility.

\section{ACKNOWLEDGEMENTS}

We thank B. Igic for references and discussion. This work was supported by National Science Foundation grant DEB-0313653 to R. L. 


\section{LITERATURE CITED}

Barrett, S. C. H. 2003. Mating strategies in flowering plants: the outcrossing-selfing paradigm and beyond. Phil. Trans. R. Soc. Lond. B. 358:991-1004.

Barrett, S. C. H, M. T. Morgan, and B. C. Husband. 1989. The dissolution of a complex genetic polymorphism: the evolution of self-fertilization in tristylous Eichhornia paniculata (Pontederiaceae). Evolution 43:1398-1416.

Bataillon, T., and M. Kirkpatrick. 2000. Inbreeding depression due to mildly deleterious mutations in finite populations: size does matter. Genet. Res. 75:75-81.

Bertin, R. I. 1993. Incidence of monoecy and dichogamy in relation to self-fertilization in Angiosperms. Am. J. Bot. 80:557-560.

Burd, M. 1994. Bateman's principle and plant reproduction: the role of pollen limitation in fruit and seed set. Bot. Rev. 60:83-139.

Byers, D. L., and D. M. Waller. 1999. Do plant purge their genetic load? Effect of population size and mating history on inbreeding depression. Ann. Rev. Ecol. Syst. 30:479-513.

Charlesworth, B., and D. Charlesworth. 1999. The genetic basis of inbreeding depression. Genet. Res. 74:329-340.

Charlesworth, D., and B. Charlesworth. 1979. The evolution and breakdown of S-allele systems. Heredity 43:41-55.

Charlesworth, D., and B. Charlesworth. 1987. Inbreeding depression and its evolutionary consequences. Ann. Rev. Ecol. Syst. 18:237-268.

Coleman, C. E., and T. H. Kao. 1992. The flanking regions of 2 Petunia inflata S-alleles are heterogeneous and contain repetitive sequences. Plant Mol. Biol. 18:725-737. 
de Nettancourt, D. 1997. Incompatibility in angiosperms. Sex. Plant. Reprod. 10:185199.

Dudash, M. R., and T. E. Carr. 1998. Genetics underlying inbreeding depression in Mimulus with contrasting mating systems. Nature 393:682-684.

Emerson, S. 1939. A preliminary survey of the Oenothera organensis population. Genetics 24:524-537.

Fenster, C. B., and S. C. H. Barrett. 1994. Inheritance of mating-system modifier genes in Eichhornia paniculata (Pontederiaceae). Heredity 72:433-445.

Fenster, C. B., and K. Ritland. 1994. Quantitative genetics of mating system divergence in the yellow monkeyflower species complex. Heredity 73:422-435.

Finney, D. J. 1952. The equilibrium of a self-incompatible polymorphic species. Genetica 26:33-64.

Fisher, R. A. 1941. Average excess and average effect of a gene substitution. Ann. Eugen. 11:53-63.

Fisher, R. A. 1958. The genetical theory of natural selection, Ed. 2. Dover, New York.

Fishman, L., A. J. Kelly, and J. H. Willis. 2002. Minor quantitative trait loci underlie floral traits associated with mating system divergence in Mimulus. Evolution $56: 2138-2155$.

Franklin-Tong, V. E., and F. C. H. Franklin. 2003. The different mechanisms of gametophytic self-incompatibility. Phil. Trans. R. Soc. Lond. B 358:1025-1032.

Georgiady, M. S., R. W. Whitkus, and E. M. Lord. 2002. Genetic analysis of traits distinguishing outcrossing and self-pollinating forms of currant tomato, Lycopersicon pimpinellifolium (Jusl.) Mill. Genetics 161:333-341.

Golz J. F., A. E. Clarke, and E. Newbigin. 2000. Mutational approaches to the study of 
self-incompatibility: Revisiting the pollen-part mutants. Ann. Bot. London 85(Suppl. A):95-103.

Harder, L. D., and W. G. Wilson. 1998. A clarification of pollen discounting and its joint effects with inbreeding depression on mating system evolution. Am. Nat. 152:684695.

Hedrick, P. W. 2002. Lethals in finite populations. Evolution 56:654-657.

Holsinger, K. E. 1991. Mass-action models of plant mating systems: the evolutionary stability of mixed mating systems. Am. Nat. 138:606-622.

Holsinger, K. E. 1996. Pollination biology and the evolution of mating systems in flowering plants. Evol. Biol. 29:107-149.

Husband, B. C., and D. W. Schemske. 1996. Evolution of the magnitude and timing of inbreeding depression in plants. Evolution 50:54-70.

Igic, B., and J. R. Kohn. 2001. Evolutionary relationships among self-incompatibility RNases. Proc. Natl. Acad. Sci. USA 98:13167-13171.

Igic, B., L. Bohs, and J. R. Kohn. 2004. Historical inferences from the selfincompatibility locus. New Phytol. 161:97-105.

Kao, T-H., and A. G. McCubbin. 1996. How flowering plants discriminate between self and non-self pollen to prevent inbreeding. Proc. Natl. Acad. Sci. USA 93:1205912065.

Klekowski, E. J., Jr., and P. J. Godfrey. 1989. Ageing and mutation in plants. Nature 340:389-391.

Kohn, J. R., and N. M. Waser. 1985. The effect of Delphinium nelsonii pollen on seed set in Ipomopsis aggregata, a competitor for hummingbird pollination. Am. J. Bot. 72:1144-1148. 
Kondo, K., M. Yamamoto, R. Itahashi, T. sato, H. Egashira, T. Hattori, and Y. Kowyama. 2002. Insights into the evolution of self-compatibility in Lycopersicon from a study of stylar factors. Plant J. 30:143-153.

Kondrashov, A. S. 1985. Deleterious mutations as an evolutionary factor. II. Facultative apomixis and selfing. Genetics 111:635-653.

Kunin, W. E. 1997. Population biology and rarity: on the complexity of densitydependence in insect plant-interactions. Pp. 150-169 in W. E. Kunin and K. J. Gaston, eds. The biology of rarity: causes and consequences of rare-common differences. Chapman and Hall, London.

Lacy, R. C., and J. D. Ballou. 1998. Effectiveness of selection in reducing the genetic load in populations of Peromyscus polionotus during generations of inbreeding. Evolution 52:900-909.

Lacy, R. C., G. Alaks, and A. Walsh. 1996. Hierarchical analysis of inbreeding depression in Peromyscus polionotus. Evolution 50:2187-2200.

Lande, R., and D. W. Schemske. 1985. The evolution of self-fertilization and inbreeding depression in plants. I. Genetics models. Evolution 39:24-40.

Lande, R., D. W. Schemske, and S. T. Schultz. 1994. High inbreeding depression, selective interference among loci, and the threshold selfing rate for purging recessive lethal mutations. Evolution 48:965-978.

Larson, B. M. H., and S. C. H. Barret. 2000. A comparative analysis of pollen limitation in flowering plants. Biol. J. Linn. Soc. 69:503-520.

Lawrence, M. J. 1996. Number of incompatibility alleles in clover and other species. Heredity 76:610-615.

Lawrence, M. J. 2000. Population genetics of the homomorphic self-incompatibility 
polymorphisms in flowering plants. Ann. Bot. London. 85(Suppl. A):221-226.

Levin, D. A., and Z. Bulinska-Radomska. 1988. Effects of hybridization and inbreeding on fitness in Phlox. Am. J. Bot. 75:1632-1639.

Li, X., N. Paech, D. Hayman, and P. Langridge. 1997. Self-incompatibility in the grasses: evolutionary relationship of the $S$ gene from Phalaris coerulescens to homologous sequences in other grasses. Plant Mol. Biol. 20:1131-1141.

Lloyd, D. G. 1992. Self- and cross-fertilization in plants. II. The selection of selffertilization. Int. J. Plant Sci. 153:370-380.

Lloyd, D. G., and D. J. Schoen. 1992. Self- and cross-fertilization in plants. I. Functional dimensions. Int. J. Plant Sci. 153:358-369.

Lloyd, D. G., and C. J.Webb. 1986. The avoidance of interference between the presentation of pollen and stigmas in Angiosperms. I. Dichogamy. New Zeal. J. Bot. 24:135-162.

Macnair, M. R., and Q. J. Cumbes. 1989. The genetic architecture of interspecific variation in Mimulus. Genetics 122:211-222.

Mather, K., and D. de Winton. 1941. Adaptation and counter-adaptation of the breeding system in Primula. Ann. Bot. London 5:297-311.

Maynard Smith, J. 1978. The evolution of sex. Cambridge University Press, Cambridge.

Mitchell, R. J. 1997. Effects of pollination intensity on Lesquerella fendleri seed set: variation among plants. Oecologia 10:382-388.

Paxman, G. J. 1963. The maximum likelihood estimation of the number of self-sterility alleles in a population. Genetics 48:1029-1032.

Reinartz, J. A., and D. H. Les. 1994. Bottleneck-induced dissolution of selfincompatibility and breeding system consequences in Aster furcatus (Asteraceae). 
Am. J. Bot. 81:446-455.

Richards, A. J. 1998. Lethal linkage and its role in the evolution of plant breeding systems. Pp. 71-83 in S. J. Owens and P. J. Rudall, eds. Reproductive biology in systematics, conservation and economic botany. Royal Botanical Garden, Kew.

Roalson, E. H., and A. G. McCubbin. 2003. S-RNases and sexual incompatibility: structure, functions and evolutionary perspectives. Mol. Phylogenet. Evol. 29:490506.

Royo, J., C. Kunz, Y. Kowyama, M. Anderson, A. F. Clarke, and E. Newbigin. 1994. Loss of a histidine residue at the active site of $S$-locus ribonuclease is associated with self-compatibility in Lycopersicon peruvianum. Proc. Natl. Acad. Sci. USA. 91:6511-6514.

Sijacic, P., X. Wang, A. L. Skirpan, Y. Wang, P. E. Dowd, A. G. McCubbin, S. Huang, and T-H. Kao. 2004. Identification of the pollen determinant of $S$-RNase-mediated self-incompatibility. Nature 429:302-305.

Simmons, M. J., and J. F. Crow. 1977. Mutations affecting fitness in Drosophila populations. Annu. Rev. Genet. 11:49-78.

Stebbins, G. L. 1957. Self fertilization and population variability in the higher plants. Am. Nat. 91:337-354.

Stebbins, G. L. 1974. Flowering plants: evolution above the species level. Harvard University Press, Cambridge.

Steinbachs, J. E., and K. E. Holsinger. 2002. S-RNase-mediated gametophytic selfincompatibility is ancestral in Eudicots. Mol. Biol. Evol. 19:825-829.

Stephenson, A. G., S. V. Good, and D. W. Vogler. 2000. Interrelationships among inbreeding depression, plasticity at the self-incompatibility system, and the 
breeding system of Campanula rapunculoides L. (Campanulaceae). Ann. Bot. London 85(Suppl. A):211-219.

Stewart, H. M., S. C. Stewart, and J. M. Canne-Hilliker. 1996. Mixed mating system in Agalinis neoscotica (Scrophulariaceae) with bud pollination and delayed pollen germination. Int. J. Plant Sci. 157:501-508.

Stone, J. L. 2002. Molecular mechanisms underlying the breakdown of gametophytic self-incompatibility. Q. Rev Biol. 77:17-32.

Stone, J. L. 2004. Sheltered load associated with S-alleles in Solanum carolinense. Heredity 92:335-342.

Tsitrone, A., S. Duperron, and P. David. 2003. Delayed selfing as an optimal mating strategy in preferentially outcrossing species: theoretical analysis of the optimal age at first reproduction in relation to mate availability. Am. Nat. 162:318-331.

Tsukamoto, T., T. Ando, K. Takahashi, T. Omori, H. Watanabe, H. Kokubun, E. Marchesi, and T-H. Kao. 2003. Breakdown of self-incompatibility in a natural population of Petunia axillaris caused by loss of pollen function. Plant Physiol. 131:1903-1912.

Ushijima, K., H. Sassa, A. M. Dandekar, T. M. Gradziel, R. Tao, and H. Hirano. 2003. Structural and transcriptional analysis of the self-incompatibility locus of almond: identification of a pollen-expressed F-box gene with haplotype-specific polymorphism. Plant Cell 15:771-778.

Uyenoyama, M. K. 1997. Genealogical structure among alleles regulating selfincompatibility in natural populations of flowering plants. Genetics 147:13891400.

Vogler, D. W., K. Filmore, and A. G. Stephenson. 1999. Inbreeding depression in 
Campanula rapunculoides L. I. A comparison of inbreeding depression in plants derived from strong and weak self-incompatibility phenotypes. J. Evol. Biol. $12: 483-494$.

Waser, N. M., and M. V. Price. 1991. Outcrossing distance effect in Delphinium nelsonii: pollen loads, pollen tubes, and seed set. Ecology 72:171-179.

Webb, C. J., and D. G. Lloyd. 1986. The avoidance of interference between the presentation of pollen and stigmas in Angiosperms. II. Herkogamy. New Zeal. J. Bot. 24:163-178.

Wright, S. 1939. The distribution of self-sterility alleles in populations. Genetics 24:538552.

Wright, S. 1968. Evolution and genetics of populations. Vol. 1. University of Chicago Press, Chicago.

Corresponding Editor: C. B. Fenster 


\section{APPENDIX}

Here we derive recursion equations for Model 1 describing the dynamics of a nonfunctional $S$-allele, with evolution of inbreeding depression due to nearly recessive lethal mutations. Equations for Model 2 (unlinked modifier locus) are similar, but with modifications in the table of crosses, selfing rate, and seed set.

In both models, the initial population is self-incompatible and therefore completely outcrossing. With no selfing and an infinite number of unlinked loci mutating to lethals, lethals never become homozygous and are selected against only as heterozygotes. The expected number of heterozygous lethals in mature plants then follows a Poisson distribution with mean denoted as $N$, and the mean fitness under a given type of mating is the negative exponential of the mean number of lethal effects per zygote caused by viability selection. On average, each generation, $U$ new lethals per genome are gained by mutation, and a proportion $1-h$ of lethals survives selection (where $h$ is the dominance coefficient of lethals), so the mean number of heterozygous lethals in mature plants of the next generation is $N^{\prime}=(N+U)(1-h)$. At equilibrium $N=U / h-U$ and the mean number of heterozygous lethals in zygotes is $N+U=U / h$. Outcrossed zygotes from this population have mean number of lethal effects $h U / h=U$. The mean fitness of outcrossed zygotes is therefore $\bar{w}_{o}=\mathrm{e}^{-U}$. The mean fitness of selfed zygotes is decreased by selection on both homozygous and heterozygous lethals. Among the $U / h-U$ heterozygous lethals inherited from the parents, under selfing $1 / 2$ remain heterozygous and die with probability $h$ and $1 / 4$ become homozygous and die. In addition, $U$ new heterozygous mutations appear and die with probability $h$. Hence, the mean number of lethal effects per selfed zygote is $(h / 2+1 / 4)(U / h-U)+U h=U(1 / h+1+2 h) / 4$ and 
their mean fitness is $\bar{w}_{s}=\mathrm{e}^{-U(1 / h+1+2 h) / 4}$. In an outcrossing population at mutationselection equilibrium, the inbreeding depression due to lethals is therefore $\delta=1-\bar{w}_{s} / \bar{w}_{o}=1-e^{-U(1 / h-3+2 h) / 4}$.

\section{General Notation}

Let $\mathrm{C}$ be the self-compatible $S$-allele and $\mathrm{I}_{\mathrm{i}}$ be any functional $S$-allele. Because isoplethy is assumed, it is not necessary to consider the different $S$-alleles and we model changes in the frequency of three categories of genotypes: $\mathrm{CC}, \mathrm{I}_{\mathrm{i}} \mathrm{C}$ (denoted IC, there are $n$ such genotypes, where $n$ is the number of $S$-alleles) and $\mathrm{I}_{\mathrm{i}} \mathrm{I}_{\mathrm{j}}$ (denoted II, there are $n(n$ 1)/2 such genotypes). Although our notation may suggest that II genotypes are homozygous, this is never the case: II genotypes are always heterozygous for functional $S$-alleles. The frequency of the $\mathrm{C}$ allele is $p_{\mathrm{C}}$ and the frequency of any functional $S$-allele is $p_{\mathrm{I}}$, hence $p_{\mathrm{C}}+n p_{\mathrm{I}}=1$.

\section{Seed Set and Selfing Rate}

\section{Delayed selfing}

Under pure delayed selfing, self pollen is deposited on the stigma at the end of anthesis (e.g. by movements of flower parts, Lloyd and Schoen 1992) and fertilizes only those ovules that have not been previously cross-fertilized. Hence, the selfing rate depends solely on pollen availability. We model delayed selfing by using a single parameter to quantify the seed set and the selfing rate. Assuming that the amount of self pollen is not limiting, self-compatible genotypes CC and partially self-compatible genotypes IC have identical selfing rate $s$; their seed set is always maximum and is 
scaled to 1 . The relative seed set of self-incompatible genotypes is $1-s$.

\section{Competing selfing}

Let $P_{s}$ and $P_{o}$ be the amount of self and outcross pollen landing on the stigma of a plant, respectively. The amount of effective pollen, i.e. pollen accepted by a given individual, depends on the genotype at the $S$-locus and is given in Table 1 for both the null allele and the modifier locus models. We use a mass-action model (Holsinger 1991), where the selfing rate is proportional to the ratio of self pollen to total pollen landing on the stigma. This leads to the following selfing rates for homozygous $(s)$ and heterozygous $\left(s^{\prime}\right)$ self-compatible plants:

$$
s=\frac{P_{s}}{P_{s}+P_{o}} \quad \text { and } \quad s^{\prime}=\frac{P_{s}}{P_{s}+2\left(1-p_{\mathrm{I}}\right) P_{o}}
$$

The total amount of effective pollen $\left(P_{\mathrm{T}}\right)$ landing on the stigma per ovule

moreover determines the relative seed set $\left(T_{\mathrm{G}}\right)$ of genotype $\mathrm{G}$ as follows (e.g. Kohn and Waser 1985; Waser and Price 1991; Mitchell 1997):

$$
T_{\mathrm{G}}=1-e^{-P_{\mathrm{T}}}
$$

Unless the amount of effective pollen is larger than 4, pollen limitation occurs. The seed set of each genotype is derived from equation (2) using the fraction of accepted pollen given in Table 1.

\section{Gamete Production and Mating}

In the following, $\mathrm{G}$ refers to diploid genotypes and $\mathrm{g}$ to haploid genotypes at the $S$-locus. Table A1 presents the frequencies of offspring zygotes with a given $S$-locus genotype carrying $x$ heterozygous lethals, originating from selfing or outcrossing of 
parents with a given $S$-locus genotype. The derivation of these frequencies is explained below.

The probability that a plant with $y$ heterozygous lethals produces, by selfing, a viable zygote with $x(\leq y)$ heterozygous lethals is $\left(\begin{array}{l}y \\ x\end{array}\right)\left(\frac{1}{2}\right)^{x}\left(\frac{1}{4}\right)^{y-x}=\left(\begin{array}{l}y \\ x\end{array}\right)\left(\frac{1}{2}\right)^{2 y-x}$ (Lande et al. 1994). Therefore, the relative frequency of zygotes with diploid genotype $G_{1}$ at the modifier locus, carrying $x$ heterozygous lethals, and originating from selfing of $\mathrm{G}_{2}$ genotypes is $q_{\mathrm{G}_{2}}^{\mathrm{G}_{1}}(x)=\sum_{y=x}^{\infty} k_{1} f_{\mathrm{G}_{2}}(y)\left(\begin{array}{l}y \\ x\end{array}\right)\left(\frac{1}{2}\right)^{2 y-x}$, where $f_{\mathrm{G}_{2}}(y)$ is the frequency of plants with $S$-locus genotype $\mathrm{G}_{2}$ carrying $y$ heterozygous lethals and $k_{1}$ is a constant accounting for Mendelian transmission of alleles at the $S$-locus $\left(k_{1}=1\right.$ or $1 / 2$ depending on the heterozygosity of $\mathrm{G}_{2}$ ). This equation describing selfing also includes selection on homozygous lethals: for genotypes carrying $x$ heterozygous lethals, a proportion $1-(3 / 4)^{x}$ of their offspring carry at least one homozygous lethal; they are not viable and are not included in the equation. For these parental genotypes, the seed set by selfing is reduced a factor $(3 / 4)^{x}$, and the sum of the equation over all parental genotypes, all offspring genotypes and all numbers of lethals is smaller than 1. Note that IC genotypes only produce CC and IC individuals by selfing, because I self pollen is always rejected.

The probability that a plant with $y$ heterozygous lethals produces a gamete with $x$ $(\leq y)$ lethals is $\left(\begin{array}{c}y \\ x\end{array}\right)\left(\frac{1}{2}\right)^{y}$. Hence, the probability that individuals with $S$-locus genotype G produce gametes with haploid $S$-locus genotype $g$ and carrying $x$ lethals is $q_{\mathrm{G}}^{\mathrm{g}}(x)=\sum_{y=x}^{\infty} k_{2} f_{\mathrm{G}}(y)\left(\begin{array}{l}y \\ x\end{array}\right)\left(\frac{1}{2}\right)^{y}$, where $k_{2}$ reflects Mendelian inheritance of the $S$-locus genotype $\left(k_{2}=1\right.$ or $1 / 2$ depending on the heterozygosity of $\left.\mathrm{G}\right)$. Assuming that all genotypes contribute equally to the pollen pool (so there is no pollen discounting 
associated with selfing), the frequencies of pollen grains carrying $x$ lethals and with $S$ locus genotype $\mathrm{C}$ and I are respectively:

$$
p_{\mathrm{C}}(x)=q_{\mathrm{CC}}^{\mathrm{C}}(x)+q_{\mathrm{IC}}^{\mathrm{C}}(x) \text { and } p_{\mathrm{I}}(x)=q_{\mathrm{II}}^{\mathrm{I}}(x)+q_{\mathrm{IC}}^{\mathrm{I}}(x) .
$$

Because each mutation is unique, random mating in an infinite population never generates homozygous lethals, and the probability that a genotype $\mathrm{G}_{2}$ produces, by outcrossing, a zygote with genotype $\mathrm{G}_{1}$ and carrying $x$ heterozygous lethals is $\sum_{y=x}^{\infty} q_{\mathrm{G}_{2}}^{\mathrm{g}_{1}}(y) p_{\mathrm{g}_{2}}(x-y)$, where $\mathrm{G}_{1}=\mathrm{g}_{1} \mathrm{~g}_{2}$ and $\mathrm{g}_{\mathrm{i}}=\mathrm{I}$ or $\mathrm{C}$. However, mating is not random in a partially self-incompatible population, since self-incompatible plants reject a fraction of outcross pollen. This affects the probability of producing a genotype by outcrossing (Table A1): as stated above, homozygous self-incompatible plants reject pollen carrying the same $S$-alleles, i.e. they are pollinated by a fraction $1-2 p_{\mathrm{I}}$ of the outcross pollen. Identically, heterozygous plants are pollinated by a fraction $1-p_{\mathrm{I}}$ of the outcross pollen (Charlesworth \& Charlesworth 1979).

The recursion equations for mating are derived from a combination of the table of crosses, seed sets and additional selective coefficients (background inbreeding depression $d$ affecting all progeny obtained by selfing, and sheltered load affecting the fitness of CC individuals, $W_{\mathrm{CC}}$ ).

$$
\begin{aligned}
f_{\mathrm{CC}}^{*}(x)=W_{\mathrm{CC}}\left[(1-d)\left(s T_{\mathrm{CC}} q_{\mathrm{CC}}^{\mathrm{CC}}(x)+s^{\prime} T_{\mathrm{IC}} q_{\mathrm{IC}}^{\mathrm{CC}}(x)\right)+(1-s) T_{\mathrm{CC}} \sum_{y=0}^{x} q_{\mathrm{CC}}^{\mathrm{C}}(y) p_{\mathrm{C}}(x-y)\right. \\
\left.+\left(1-s^{\prime}\right) T_{\mathrm{IC}} \sum_{y=0}^{x} q_{\mathrm{IC}}^{\mathrm{C}}(y) \frac{p_{\mathrm{C}}(x-y)}{1-p_{\mathrm{I}}}\right] \\
f_{\mathrm{IC}}^{*}(x)=(1-d) s^{\prime} T_{\mathrm{IC}} q_{\mathrm{IC}}^{\mathrm{IC}}(x)+(1-s) T_{\mathrm{CC}} \sum_{y=0}^{x} q_{\mathrm{CC}}^{\mathrm{C}}(y) p_{\mathrm{I}}(x-y)+T_{\mathrm{II}} \sum_{y=0}^{x} q_{\mathrm{II}}^{\mathrm{I}}(y) \frac{p_{\mathrm{C}}(x-y)}{1-2 p_{\mathrm{I}}}
\end{aligned}
$$




$$
\begin{array}{r}
+\left(1-s^{\prime}\right) T_{\mathrm{IC}} \sum_{y=0}^{x}\left(q_{\mathrm{IC}}^{\mathrm{C}}(y) \frac{(n-1) p_{\mathrm{I}}(x-y)}{1-p_{\mathrm{I}}}+q_{\mathrm{IC}}^{\mathrm{I}}(y) \frac{p_{\mathrm{C}}(x-y)}{1-p_{\mathrm{I}}}\right) \\
f_{\text {II }}^{*}(x)=\left(1-s^{\prime}\right) T_{\mathrm{IC}} \sum_{y=0}^{x} q_{\mathrm{IC}}^{\mathrm{I}}(y) \frac{p_{\mathrm{I}}(x-y)}{1-p_{\mathrm{I}}}+T_{\mathrm{II}} \sum_{y=0}^{x} q_{\mathrm{II}}^{\mathrm{I}}(y) \frac{(n-2) p_{\mathrm{I}}(x-y)}{1-2 p_{\mathrm{I}}}
\end{array}
$$

\section{Mutation and Selection due to Nearly Recessive Lethals}

Mutation to nearly recessive lethals follows a Poisson process, with a mean number of new heterozygous lethal mutations per genome of $U$ per generation. The frequencies of zygotes after mutation are therefore, for any diploid genotype G:

$$
f_{\mathrm{G}}^{* *}(x)=\sum_{y=0}^{x} f_{\mathrm{G}}^{*}(x-y) \frac{e^{-U} U^{y}}{y !}
$$

The probability that a zygote with $x$ heterozygous mutations survives to maturity is $(1-h)^{x}$. The frequency of mature plants with $x$ heterozygous lethals in the next generation is then, for any genotype:

$$
f_{\mathrm{G}}^{\prime}(x)=\frac{(1-h)^{x}}{\bar{W}} f_{\mathrm{G}}^{* *}(x)
$$

$\bar{W}$ is the mean fitness of a population:

$$
\bar{W}=\sum_{x=0}^{\infty}(1-h)^{x}\left[f_{\mathrm{CC}}^{* *}(x)+f_{\mathrm{IC}}^{* *}(x)+f_{\mathrm{II}}^{* *}(x)\right]
$$

Equations (1) to (8) completely define the recursion system. For each run, a small frequency of the self-compatible allele was introduced in linkage equilibrium with lethals and $S$-alleles, into an initially self-incompatible population at equilibrium for lethals. Simulations were run until the system closely approached a new equilibrium. 


\section{FIGURE CAPTIONS}

FIG. 1. Conditions for invasion of a self-incompatible population by a non-functional $S$ allele (Model 1). The critical inbreeding depression due to lethals, $\delta$, above which invasion cannot occur, is plotted against the selfing rate, $s$, of the homozygous selfcompatible genotype CC, under various conditions of pollen limitation (amount of outcross pollen landing on the stigma per ovule $P_{o}: \cdots=0.5, \cdots=1, \boldsymbol{-}=2, \boldsymbol{-}=3$, $\mathbf{-}=\infty)$, number of $S$-alleles $(n=\infty, 50$, and 10$)$, background inbreeding depression ( $d=0$ and 0.25$)$, and genetic load linked to the self-compatible allele ( $1-W_{\mathrm{CC}}=0$ and 0.5). The selfing rates of the homozygous CC genotype, $s$, and of the heterozygous $\mathrm{CI}_{\mathrm{i}}$ genotypes, $s^{\prime}$, are given in Table 1 as a function of the amount of self and outcross pollen $P_{s}$ and $P_{o}$ landing on the stigma.

FIG. 2. Stable polymorphism for SI when self-compatibility is due to a non-functional $S$ allele (Model 1). Contours of equilibrium frequency of the self-compatible $\mathrm{C}$ allele, $p_{\mathrm{C}}$, in two situations. A. Finite number of $S$-alleles $(n=50)$, low selfing rate, no background inbreeding depression $(d=0)$ and no sheltered load $\left(1-W_{\mathrm{CC}}=0\right)$. The critical value of $\delta$ preventing the spread of the self-compatible allele (thick line for $p_{\mathrm{C}}=0$ ) is reproduced from Figure 1B (no pollen limitation). Contour lines are, from the left to the right: $p_{\mathrm{C}}=1,0.9 \ldots 0.1,0 . \mathrm{B}$. Infinite number of $S$-alleles $(n=\infty)$, background inbreeding depression $(d=0.25)$ and sheltered load $\left(1-W_{\mathrm{CC}}=0.5\right)$. The critical value of $\delta$ preventing the spread of a self-compatible allele (thick line for $p_{\mathrm{C}}=0$ ) is reproduced from Figure $1 \mathrm{G}$ (no pollen limitation). Contour lines are, from the left to the right: $p_{\mathrm{C}}=0,0.01,0.05,0.1,0.2 \ldots 0.9$. The scales of the $\mathrm{x}$ and $\mathrm{y}$-axis differ between $\mathrm{A}$ and $\mathrm{B}$. 
This figure presents two examples of stable polymorphisms only, but such polymorphisms can be observed in every case of either finite number of $S$-alleles and low selfing rate $(\mathrm{A})$, or sheltered load (B).

FIG. 3. Conditions for invasion of a self-incompatible population by a self-compatible allele at a modifier locus unlinked to the $S$-locus (Model 2). The critical inbreeding depression due to lethals, $\delta$, above which invasion cannot occur, is plotted against the selfing rate, $s$, of the homozygous self-compatible genotype ( $\mathrm{mm})$, for various conditions of pollen limitation (amount of outcross pollen $P_{o}: \cdots=0.5, \cdots=1,-=2$, $\boldsymbol{-}=3, \boldsymbol{=}=\infty)$, number of $S$-alleles $(n=\infty, 50$, and 10), background inbreeding depression $(d=0$ and 0.25$)$, and sheltered load $\left(1-W_{\mathrm{CC}}=0\right.$ and 0.5$)$. The selfing rates of the homozygous genotype mm, $s$, and of the heterozygous genotypes $\mathrm{MmI}_{\mathrm{i}} \mathrm{I}_{\mathrm{j}}, s^{\prime}$, and $\mathrm{MmI}_{\mathrm{i}} \mathrm{I}_{\mathrm{i}}, s^{\prime \prime}$, are given in Table 1 as a function of the amount of self and outcross pollen $P_{s}$ and $P_{o}$ landing on the stigma.

FIG. 4. Stable polymorphism for SI when self-compatibility is due to a modifier locus (Model 2). The figure presents contour plots of the equilibrium value of the frequency of the self-compatible allele at the modifier locus, $p_{\mathrm{m}}$, with a finite number of $S$-alleles $(n=50)$, moderate pollen limitation $\left(P_{o}=3\right)$, background inbreeding depression $(d=0.25)$ and sheltered load $\left(1-W_{\mathrm{CC}}=0.5\right)$. The critical value of $\delta$ preventing the spread of the self-compatible allele (thick line for $p_{\mathrm{m}}=0$ ) is reproduced from Figure $3 \mathrm{H}$. Contour lines are, from the left to the right: $p_{\mathrm{m}}=1,0.8,0.6$, and 0.4 . 
TABLE 1. Amount of effective self and outcross pollen, and resulting selfing rates, as a function of the plant genotype.

Effective pollen is accepted by the style and able to fertilize the ovules. Model 1 concerns a self-compatible (non-functional) $S$-allele; Model 2 describes inactivation of the $S$-locus in the style by an unlinked modifier locus. $P_{s}$ and $P_{o}$ are the amount of self and outcross pollen landing on the stigma, $p_{\mathrm{I}}$ is the frequency of any $S$-allele (assuming isoplethy), and $h_{p}=1 / 2$ is the dominance coefficient of the modifier allele (Model 2).

\begin{tabular}{|c|c|c|c|c|c|}
\hline & Genotype & SI phenotype & $\begin{array}{l}\text { Effective self } \\
\text { pollen }\end{array}$ & $\begin{array}{l}\text { Effective outcross } \\
\text { pollen }\end{array}$ & Selfing rate \\
\hline \multirow{3}{*}{$\begin{array}{l}\text { Model } \\
1\end{array}$} & $\mathrm{CC}$ & Self-compatible & $P_{s}$ & $P_{o}$ & $s=\frac{P_{s}}{P_{s}+P_{o}}$ \\
\hline & $\mathrm{CI}_{\mathrm{i}}$ & $\begin{array}{l}\text { Partially self- } \\
\text { compatible }\end{array}$ & $P_{s} / 2$ & $\left(1-p_{\mathrm{I}}\right) P_{o}$ & $s^{\prime}=\frac{P_{s}}{P_{s}+2\left(1-p_{I}\right) P_{o}}$ \\
\hline & $\mathrm{I}_{\mathrm{i}} \mathrm{I}_{\mathrm{j}}$ & Self-incompatible & 0 & $\left(1-2 p_{\mathrm{I}}\right) P_{o}$ & 0 \\
\hline \multirow{6}{*}{$\begin{array}{l}\text { Model } \\
2\end{array}$} & $\begin{array}{l}\mathrm{mmI}_{\mathrm{i}} \mathrm{I}_{\mathrm{j}} \\
\mathrm{mmI}_{\mathrm{i}} \mathrm{I}_{\mathrm{i}}\end{array}$ & Self-compatible & $P_{s}$ & $P_{o}$ & $s=\frac{P_{s}}{P_{s}+P_{o}}$ \\
\hline & & \multirow{2}{*}{$\begin{array}{l}\text { Partially self- } \\
\text { compatible }\end{array}$} & $h_{p} P_{\mathrm{s}}$ & {$\left[1-2 p_{\mathrm{I}}\left(1-h_{p}\right)\right] P_{o}$} & $s^{\prime}=\frac{h_{p} P_{s}}{h_{p} P_{s}+\left[1-2 p_{I}\left(1-h_{p}\right)\right] P_{o}}$ \\
\hline & $\mathrm{MmI}_{\mathrm{i}} \mathrm{I}_{\mathrm{i}}$ & & $h_{p} P_{\mathrm{s}}$ & {$\left[1-p_{\mathrm{I}}\left(1-h_{p}\right)\right] P_{o}$} & $s^{\prime \prime}=\frac{h_{p} P_{s}}{h_{p} P_{s}+\left[1-p_{I}\left(1-h_{p}\right)\right] P_{o}}$ \\
\hline & $\mathrm{MMI}_{\mathrm{i}} \mathrm{I}_{\mathrm{j}}$ & \multirow{3}{*}{ Self-incompatible } & 0 & $\left(1-2 p_{\mathrm{I}}\right) P_{o}$ & 0 \\
\hline & & & & & \\
\hline & $\mathrm{MMI}_{\mathrm{i}} \mathrm{I}_{\mathrm{i}}$ & & 0 & $\left(1-p_{\mathrm{I}}\right) P_{o}$ & 0 \\
\hline
\end{tabular}




\section{APPENDIX TABLE}

TABLE A1: Table of crosses when the breakdown of SI is due to a non-functional $S$ allele (modified from Charlesworth and Charlesworth 1979). The table contains the frequencies of $S$-locus offspring genotypes with $x$ heterozygous lethals originating from selfing or outcrossing of $S$-locus parental genotypes.

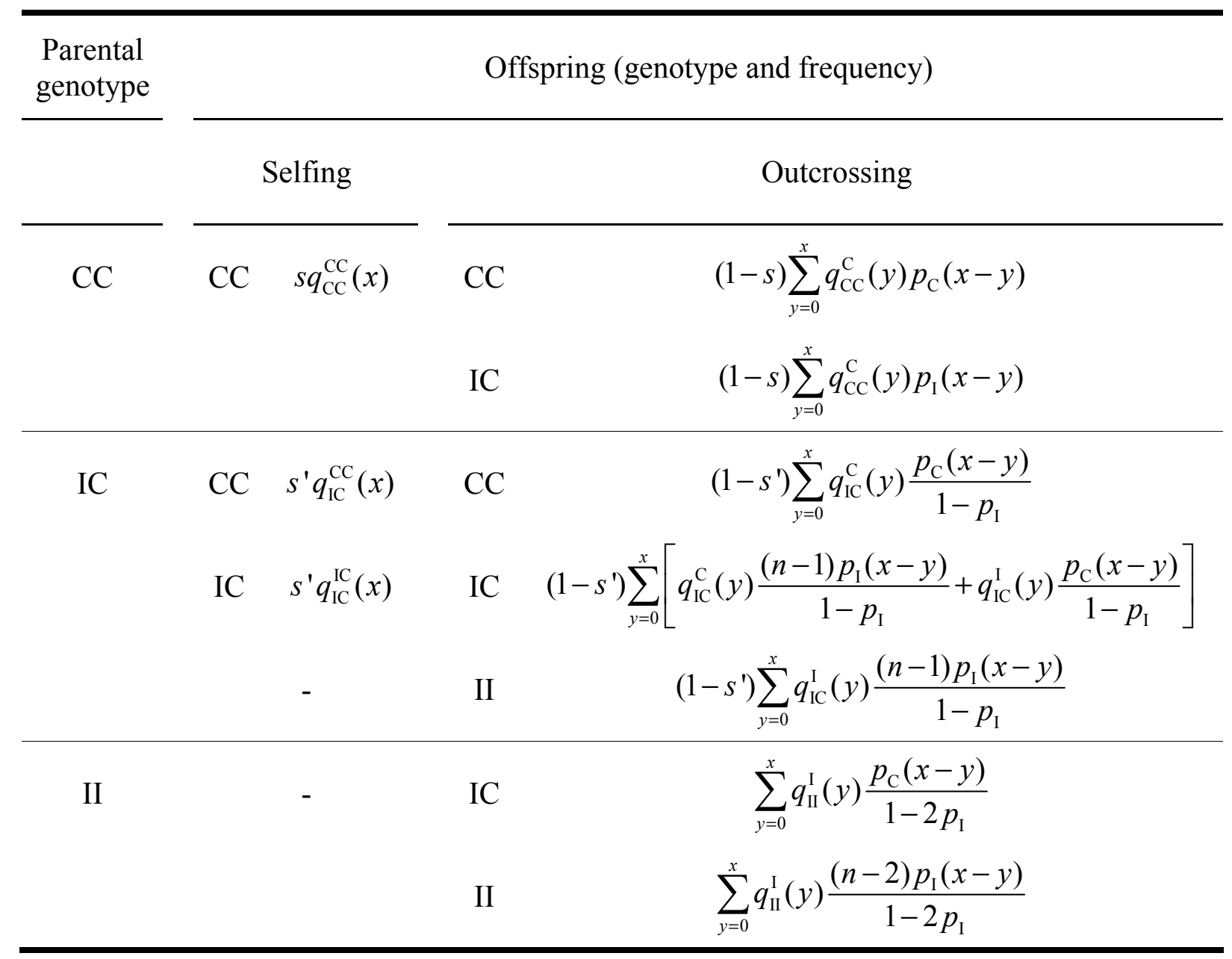




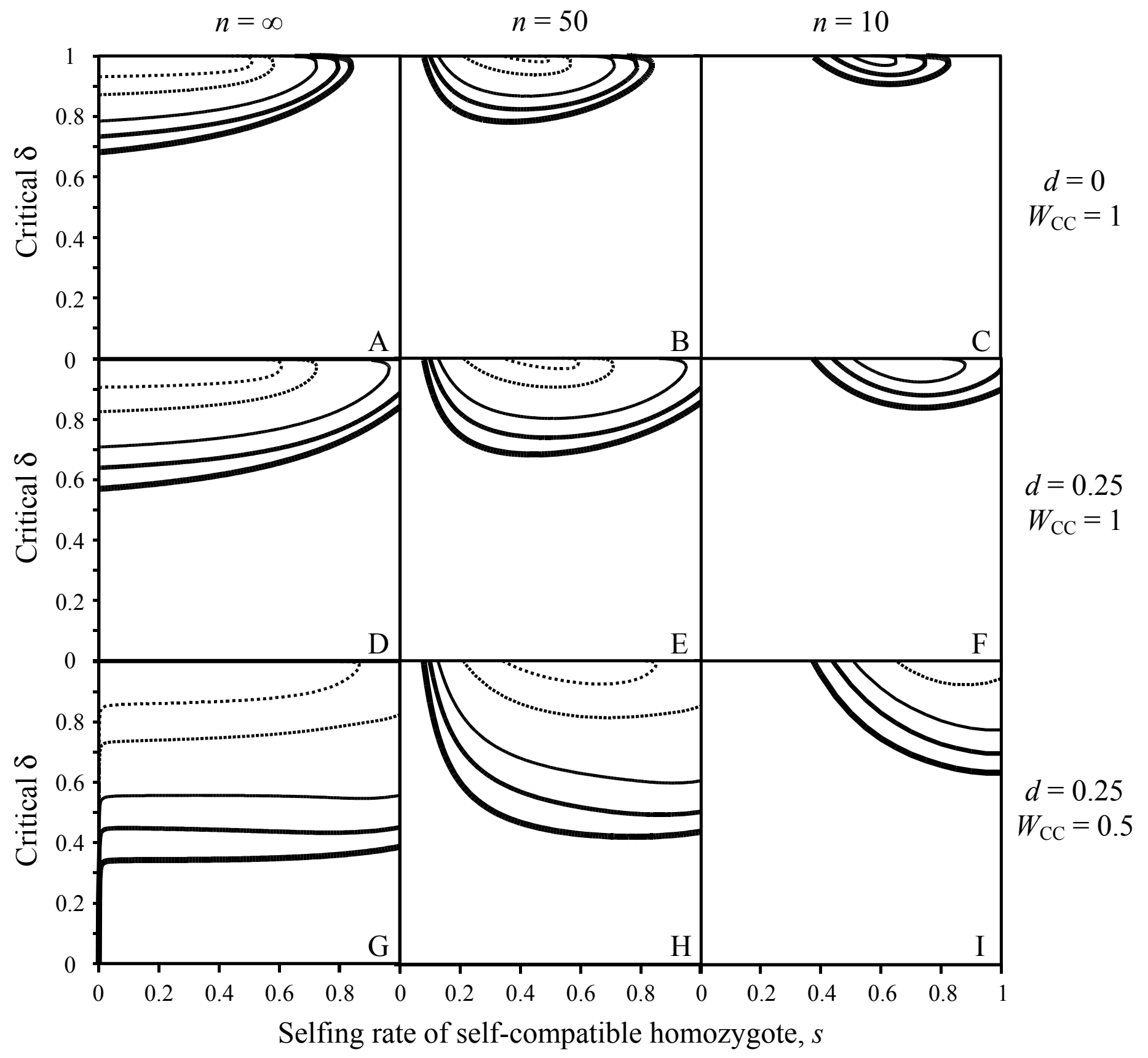




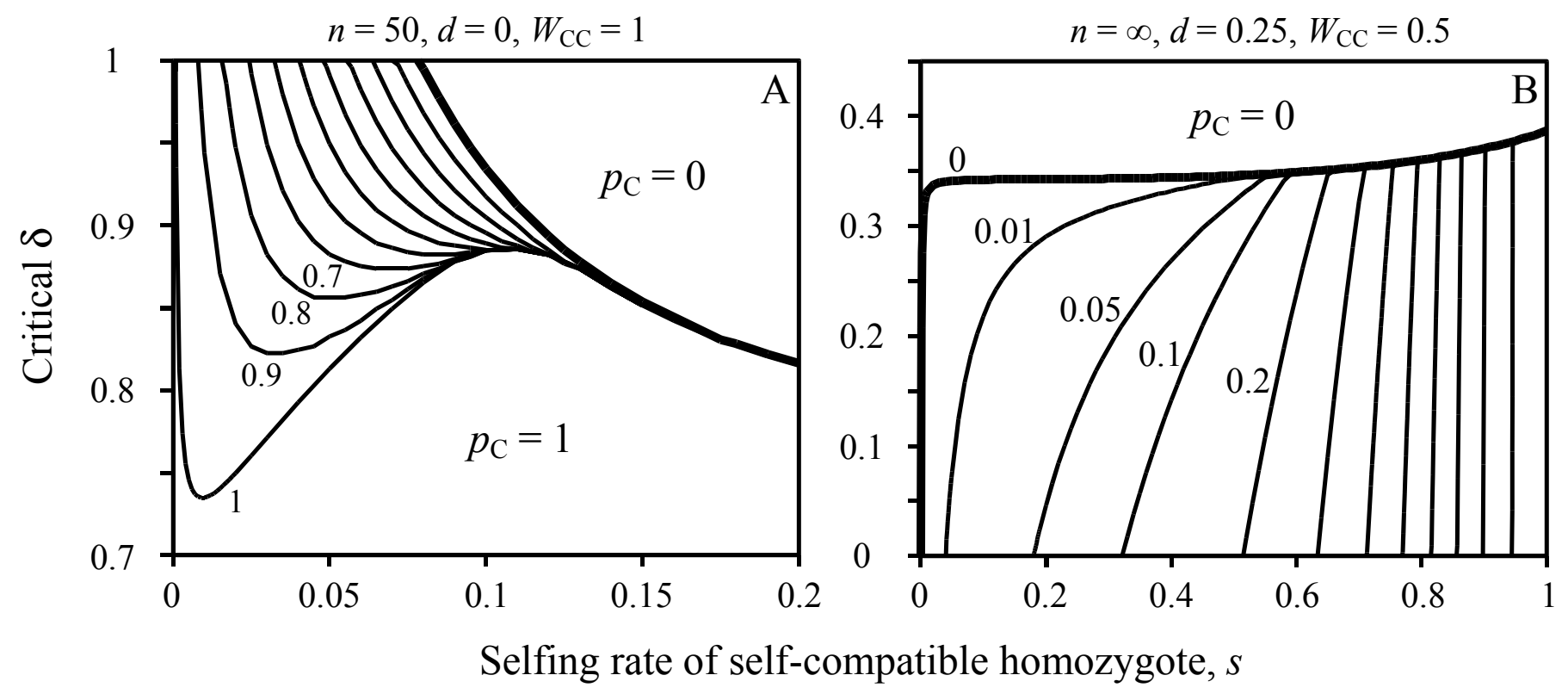




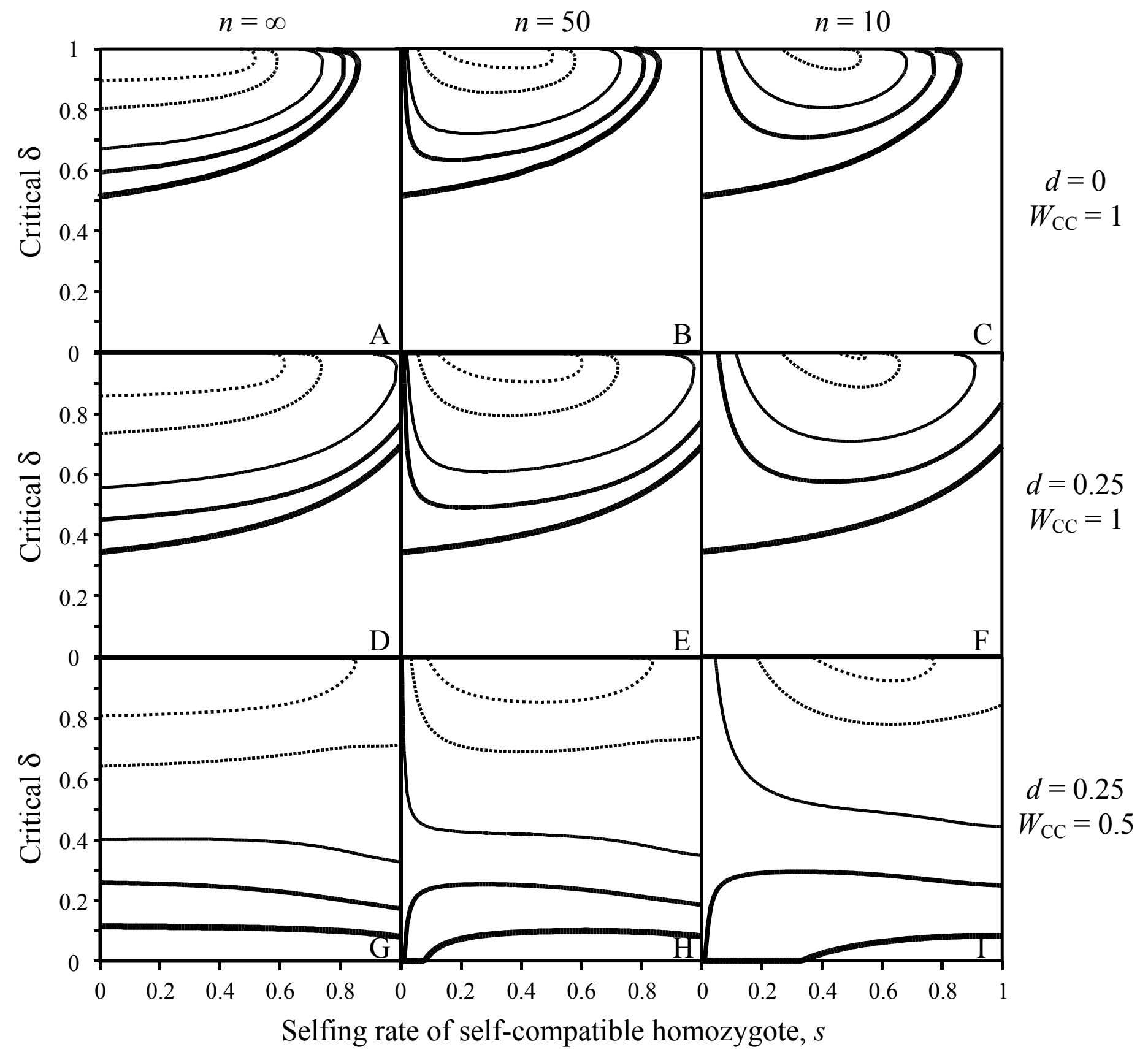




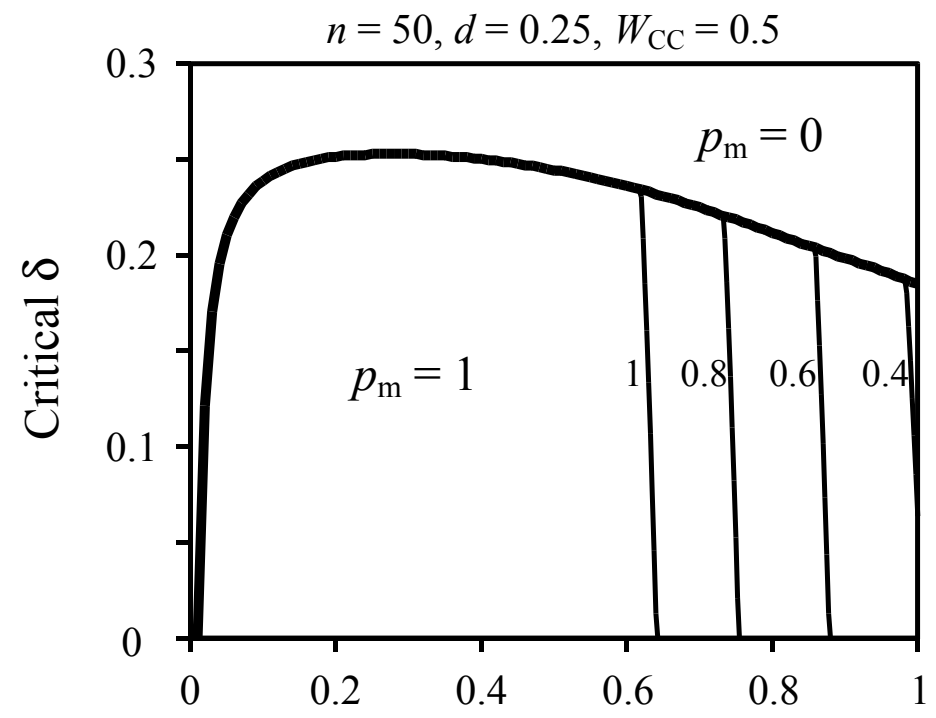

Selfing rate of self-compatible homozygote, $s$ 